\title{
PRÁTICAS DE LINGUAGEM EM SALA DE AULA COMO REVELADORAS DE MUDANÇAS NA PROFISSIONALIDADE DOCENTE
}

\author{
Ana Maria de Mattos Guimarães \\ Fernanda Vanessa Machado Bartikoski ${ }^{*}$ \\ Universidade do Vale do Rio dos Sinos \\ Escola da Indústria Criativa \\ São Leopoldo, RS, Brasil
}

\begin{abstract}
Resumo: Este artigo reflete sobre a importância de analisar as interações professor-aluno como parte da profissionalidade do professor, projetando sua capacidade de pilotar um projeto de ensino predeterminado (BRONCKART, 2006). Em outras palavras, que pode, durante o curso de seu agir, ser modificado pelas possibilidades de coconstrução do conhecimento em sala de aula. Para mostrar este movimento, o artigo traz exemplos de interações de uma das professoras participantes de projeto de formação continuada cooperativa. Ao ressignificar o conceito de linguagem nas práticas de interação com os alunos, enfim, em seu trabalho real/concretizado (GUIMARÃES et al., 2012), ela revela uma articulação entre o que aprendeu no decorrer da formação e sua prática profissional, notada sobretudo na constante prática do revozeamento (O'CONNOR; MICHAELS, 1996). Ressalta-se, então, a necessidade de formações que repensem o ensino de Língua Portuguesa em um processo que enfatiza a importância das interações professor-alunos.
\end{abstract}

Palavras-chave: Língua materna. Ensino. Interação. Agir docente.

1 INTRODUÇÃO

ANA

ALUNO-DUDA

ANA

ALUNO-DUDA

ANA

ALUNA 2

ANA

ALUNOS

(S2 - Aula 1_30_06_14)
O que que é o autorretrato então?

É uma coisa assim ((o aluno forma um quadrado com as mãos))

É uma folha assim?

É uma foto

A:::h é uma foto m::: o que mais pode ser um autorretrato? ((silêncio)) Será que só a foto é um autorretrato?

Tem que escrever o que que a pessoa gosta

Tem que escrever o que que a pessoa $\uparrow$ gosta m::: o que ma::is $>$ que vocês< sabem sobre o autorretrato? A foto que o Duda falou é qualquer foto?

Nã:::o ((todos respondem juntos))

\footnotetext{
* Professora Titular do Programa de Pós-Graduação em Linguística Aplicada e Bolsista de Produtividade em Pesquisa do CNPq. E-mail: anamguima@terra.com.br

** Doutoranda no Programa de Pós-Graduação em Linguística Aplicada (UNISINOS) e Mestra pelo mesmo Programa. Bolsista CAPES. E-mail: femachadobart@gmail.com.
} 
Inauguramos este $\operatorname{artigo~}^{1}$ com um excerto de interação entre a professora Ana (nome fictício) com sua turma de $1^{\circ}$ ano do Ensino Fundamental, no momento em que ela questiona os alunos sobre o gênero que será objeto de estudo através de um Projeto Didático de Gênero. Ana havia participado de formação continuada cooperativa de professores de Língua Portuguesa, a partir da qual foi construída a noção de Projeto Didático de Gênero (PDG) (GUIMARÃES; KERSCH, 2012, 2014 e 2015)². Os dados gerados a partir desse projeto constituem-se em uma fonte de reflexão para novas ações ${ }^{3}$. Objetiva-se, a partir dessas reflexões, propor novas formações, que repensem o ensino de Língua Portuguesa em um processo que enfatiza a importância das interações professor/alunos para a didatização de gêneros aliada às práticas sociais.

No presente artigo, destacaremos o conceito que, a nosso ver, embasa a possibilidade de se mudar de paradigma no ensino de língua materna: o da linguagem vista como interação. Essa mudança parte do abandono de uma concepção tradicional, beletrista e apoiada na gramática tradicional, por uma concepção que entende linguagem como interação.

Procuraremos descrever, do ponto de vista linguístico-interacional, a forma como esse conceito, trabalhado na formação - de ordem epistemológica portanto, se atualiza na práxis da transposição didática e se (re)configura nas interações professor-alunos.

\section{AS CONCEPÇÕES DE LINGUAGEM E SUAS IMPLICAÇÕES NO ENSINO DE LÍNGUA}

No trabalho clássico de João Wanderlei Geraldi ([1984] 1991), o autor aponta três concepções de linguagem: (1) linguagem como expressão do pensamento, (2) linguagem como instrumento de comunicação e (3) linguagem como forma de interação.

Ligada aos estudos tradicionais, a primeira concepção apregoa a ideia de que as pessoas que não conseguem se expressar não pensam, sob a perspectiva de que a língua é um sistema individual, que traduz o pensamento do falante. Nesse viés, na escola, o domínio das linguagens (oral e escrita) é determinado pelo domínio da teoria gramatical. Como resultado, o ensino fica pautado na transmissão do conhecimento, um processo mecânico, que acaba atribuindo ao aluno um papel passivo na aprendizagem.

A segunda concepção, linguagem como instrumento de comunicação, tem suas bases consolidadas no estruturalismo, entendendo a língua como um código (conjunto de

\footnotetext{
${ }^{1}$ Agradecemos ao colega Professor Anderson Carnin pelas discussões a respeito do artigo, que muito auxiliaram nossas reflexões. Da mesma forma, agradecemos a leitura atenta dos/as pareceristas, que contribuíram para o aprimoramento da versão final deste artigo.

2 Essa formação foi parte do projeto apoiado pelo Programa Observatório da Educação da CAPES, entre os anos de 2011 e 2014, intitulado "Por uma formação continuada cooperativa para o desenvolvimento do processo educativo de leitura e produção textual escrita no Ensino Fundamental" (FORMCOOP). Tal projeto, a partir do qual foram gerados os dados em análise, tratou da possibilidade de constituir, de forma cooperativa, em conjunto com professores do Ensino Fundamental, a mudança de paradigmas presentes quando se pensa no ensino de língua materna na Educação Básica.

${ }^{3}$ Este artigo emana de projeto atualmente desenvolvido por Guimarães e do qual Bartikoski faz parte. Tratase de "O professor de Língua Portuguesa em sala de aula: reflexões para ação", que conta com apoio do CNPq, Edital de Produtividade em Pesquisa.
} 
signos que se combinam por meio de regras) que transmite do emissor para o receptor uma determinada mensagem. Pautada nessa ideia, essa concepção compreende a língua fora de seu contexto de uso e, ainda, sinaliza que, para se comunicar, o falante precisa apenas aprender o sistema de códigos de sua língua. Em termos educacionais, entender linguagem como instrumento de comunicação impacta no trabalho em sala de aula, pois leva a uma abordagem de ensino que perpetua uma compreensão de língua como sistema linguístico, desvinculado do contexto sociocultural, e, por isso, menos influenciado pelo que é coconstruído pelo sujeito no uso da linguagem.

É à linguagem como forma de interação a que a formação continuada proposta pelo grupo FORMCOOP e, por consequência, o PDG se alinham. Nessa concepção, a interação humana se constitui por meio da linguagem, com sujeitos ativos em diálogo (cf. VOLOCHINOV, 2006; BAKHTIN, 2011). Contrapondo-se às duas concepções já elencadas, o estudo da linguagem se dá em situações de uso da língua, uma vez que é na interação que o sujeito age e se relaciona com o outro e com o mundo.

Acreditamos que a opção por uma dessas concepções não é neutra, mas significa uma opção política que envolve uma visão da realidade escolar, o que ocorre da mesma forma com opções metodológicas de ensino, as quais se relacionam fortemente às teorias de linguagem, que seguem as concepções arroladas. Assim, escolher trabalhar apenas com gramática, dentro de um normativismo exacerbado, utilizando textos para extração de informações, envolve a opção de se imaginar correspondências exatas, regularidades precisas, o que se contrapõe à própria complexidade da linguagem. Também entender que só há uma leitura possível de um texto, seja qual ele for, compreender leitura como decodificação, mostra a prática talvez ingênua da escola como local de reprodução, de olhar o aluno como passivo diante de um texto proposto com uma única visão de mundo (a do livro didático, muitas vezes).

Por outro lado, entender linguagem como interação não significa ignorar a formalização. Carlos Franchi (1992, p. 10) fala muito bem a respeito ao mostrar que essa concepção, vista como atividade construtivista, não pode nos levar ao que chama de um mal-entendido inverso:

\footnotetext{
[...] na medida em que se reafirma o caráter histórico e o condicionamento contextual das línguas naturais, a irredutibilidade de seus processos expressivos a um sistema formal, podese estimular uma atitude epistemológica ingênua de imediata recusa de formalização. E, ao contrário, nos parece que o que se deve esperar é que os modelos formais se elaborem a um nível bem maior de abstração. Gostaríamos de recordar, nesse sentido, a complementaridade desses 'momentos'- nunca termos mas instantes de um processo cíclico intermitente: reflexão filosófica, investigação experimental, elaboração teórica. Que todos supõem não uma concepção estreita do objeto a descrever, no caso a linguagem, mas uma consciência clara de sua complexidade.
}

É a partir da concepção de linguagem como interação que podemos sustentar conceitos básicos para a aula de Língua Portuguesa, como leitura vista como uma atitude responsiva ativa (VOLOCHINOV, 2006; BAKHTIN, 2011); gênero entendido como cadeias de pensamento (BAKHTIN, 2011), como organização relativamente estável de enunciados; tex to como unidade comunicativa global (BRONCKART, 1999) e ensino de análise linguística como decorrência das necessidades demonstradas pelo conjunto de 
textos dos alunos em conjunção com o(s) gênero(s) de texto escolhido(s). Aliada à mesma concepção está a necessidade de inserirmos o produto dessas aulas em uma prática social que se vincule à comunidade em que estão inseridos os alunos e a possibilidades de entenderem outras práticas que poderão ajudá-los no desenvolvimento de suas capacidades de linguagem e de agir. Esses são os fundamentos dos Projetos Didáticos de Gênero - PDG (GUIMARÃES; KERSCH, 2012, 2014, 2015).

Essa proposta trouxe como diferencial o fato de ser um projeto, voltado, portanto, para uma sequência de atividades que se realizam dentro e fora da escola, de forma a garantir que o(s) gênero(s) tratado(s) esteja $(\mathrm{m})$ realmente ligado(s) a uma prática social (GUIMARÃES; KERSCH, 2015). A noção de sequência didática de Schneuwly e Dolz (2004) inspira as atividades com gêneros contempladas pela proposta metodológica aqui descrita. Assim, propõe-se que em um PDG:

- a leitura (incluindo a do não-verbal e a do multissemiótico) e escrita tenham a mesma importância;

- a leitura seja entendida como diálogo entre os sentidos atribuídos ao texto por seu autor e aqueles dados pelo seu leitor, por sua vez, transformado em autor (VOLOCHINOV, 2006);

- atribua-se destaque ao sentido, tanto na leitura como na escrita, pensando que está sendo coconstruído na e para a interação social;

- focalize-se, no máximo, dois gêneros, numa relação clara com as práticas sociais da comunidade à qual se destina;

- enfatize-se a circulação dos textos produzidos, numa preocupação com a interlocução projetada.

Dessa forma, na concepção desenvolvida (GUIMARÃES; KERSCH, 2015), o PDG representa uma coconstrução de conhecimento para uma prática social que possa se inscrever em situações significativas para os aprendizes e para seus docentes. Vários estudos, muitos dos quais constituíram teses e dissertações de Mestrado e Doutorado, já foram apresentados sobre $\mathrm{PDG}^{4}$. Análises realizadas por Bartikoski (2017), em sua dissertação de Mestrado, ajudam a exemplificar uma possibilidade de concretizar a difícil tarefa de avaliar um projeto de gênero após sua execução. Neste artigo, nos valemos desse estudo, seguindo a professora Ana, ao planejar e desenvolver um PDG sobre o gênero autorretrato, tendo o objetivo de que seus alunos de $1^{\circ}$ ano se apresentassem aos membros do conselho de classe, durante sua primeira reunião do ano. Como sabemos, na maior parte dos conselhos de classe, os alunos são apresentados pela professora, que mostra seu ponto de vista com relação aos aprendizes. Ana, entretanto, quer fazer diferente, quer coconstruir com seus alunos a imagem que será apresentada aos demais membros do conselho de classe. $\mathrm{O}$ gênero autorretrato está, pois, a serviço de uma prática social do âmbito escolar.

\footnotetext{
${ }^{4}$ Para saber mais, ver Almeida (2015), Bartikoski (2013), Bartholomeu (2016), Braga (2016), Carnin (2015), Lisboa (2014) e Marques (2014) nas referências deste trabalho. 


\section{DO TRABALHO DO PROFESSOR E DE SUA PROFISSIONALIDADE}

Estamos tomando como teoria de base o interacionismo sociodiscursivo (ISD), proposto por Bronckart e seguidores (1999, 2006, 2008), com o objetivo de realizar parte do projeto do interacionismo social, sempre tendo como foco de análise o que as potencialidades do sujeito tornam possível no plano da linguagem. O estudo das atividades de linguagem é feito através dos textos (orais e escritos) que as materializam. Tais textos são considerados unidades comunicativas globais e se agrupam em gêneros, "[...] que são socialmente indexados, quer dizer, que são reconhecidos como pertinentes e/ou adaptados para uma situação comunicativa dada." (BRONCKART, 2004, p. 115). A noção de gênero, cuja diversidade é potencialmente ilimitada, é tomada de Bakhtin (2011, p. 262-3), para quem

[...] o emprego da língua efetua-se em forma de enunciados (orais e escritos) concretos e únicos, proferidos pelos integrantes desse ou daquele campo de atividade humana [...]. Evidentemente, cada enunciado particular é individual, mas cada campo de utilização da língua elabora seus tipos relativamente estáveis de enunciados, os quais denominamos gêneros de discurso.

Dentro do quadro interacionista sociodiscursivo, Bronckart (2004) conceitua o trabalho como constitutivo de uma forma de agir, uma prática comum à espécie humana. $\mathrm{O}$ autor justifica a necessidade de se pensar o ensino como trabalho, através da perspectiva do professor. Lembra a evolução natural dos trabalhos de didática das disciplinas e, consequentemente, a necessidade de análise dos resultados de aplicação das novas teorias didáticas em sala de aula e da reação de alunos e professores frente a elas.

Como já foi amplamente discutido, o trabalho docente é extremamente complexo (cf. BRONCKART, 2008). O professor precisa mobilizar-se, integralmente, em diferentes situações para possibilitar a aprendizagem de seus alunos. Essas situações incluem planejamento, aulas, avaliações, preparação de outras atividades. Para isso, o professor deve orientar-se por prescrições pré-estabelecidas por diferentes instâncias superiores, além de contar, para a realização de seu trabalho, "[...] com a utilização de instrumentos obtidos do meio social e na interação com diferentes outros que, de forma direta ou indireta, estão envolvidos na situação." (MACHADO, 2007, p. 93). Assim, o trabalho do professor nem sempre depende apenas dele mesmo para sua realização, mas somam-se outras dimensões que também são constituintes de seu trabalho. Entendemos que uma dessas dimensões deve incluir não só a formação inicial do docente, mas também sua formação continuada, objeto desta pesquisa.

Bronckart (2006) relaciona a profissionalidade do professor à capacidade de pilotar um projeto pedagógico e de gerenciar, ao mesmo tempo, as intervenções e as necessidades distintas dos alunos, juntamente com as diversas situações que ocorrem na classe.

Para entender como o professor representa sua profissionalidade, e, nos casos do projeto em pauta, como o docente representa a possível transformação de sua práxis ao longo da formação continuada, debruçamo-nos sobre o trabalho real. Pensa-se no trabalho real/concretizado. Analisa-se a dimensão do que Bronckart (2006) denomina de real mais 
concreto, tomado apenas como o que é efetivamente realizado em uma situação de trabalho, ou seja, “[...] os modos como a linguagem medeia a interação entre professor, aluno(s) e objeto de ensino no processo de ensino-aprendizagem em sala de aula de língua portuguesa" (GUIMARÃES et al., p. 157). A posição interacionista sociodiscursiva, portanto, considera a relevância e pertinência das análises das interações, sem, contudo, negar a existência de uma realidade sócio-historicamente construída e composta de valores, normas etc. que precisam necessariamente ser levados em conta no processo analítico (cf. MALABARBA, 2015).

Para exemplificar o que falamos, seguiremos a professora Ana durante a pilotagem de seu projeto de ensino, ou seja, seu PDG sobre o gênero autorretrato.

\section{DOS CONCEITOS BÁSICOS DE UM PDG À SUA RECONFIGURAÇÃO NO TRABALHO DO PROFESSOR: VERIFICANDO AS PRÁTICAS DE LINGUAGEM REVELADORAS DA CONCEPÇÃO DE LINGUAGEM NELE DESENVOLVIDA}

A concepção de linguagem como interação ocupa um lugar central na proposta de PDG, pois ela embasa os demais pilares que o sustentam: gênero de texto, leitura, letramento e prática social, análise linguística. Uma das formas de verificar se a concepção de linguagem defendida pela formação estaria presente na sala de aula da professora Ana é a partir da análise de suas interações com seus alunos. Utilizando estudos de Conceição e Garcez (2005) e Garcez (2006), que tratam da questão da falaem-interação em sala de aula no contexto brasileiro, vemos que as práticas institucionais da sala de aula podem ser analisadas sob o foco da análise da conversa. No caso em pauta, duas práticas serão analisadas: a sequência triádica Iniciação-Resposta-Avaliação (sequência IRA) e o revozeamento.

A estrutura conversacional conhecida como sequência IRA, descrita inicialmente por Sinclair e Coulthard (1975), é muito recorrente em sala de aula. Essa sequência atribui ao professor um papel central na interação, uma vez que é ele quem faz uma pergunta da qual normalmente já sabe a resposta, para um aluno que responde, muitas vezes, tentando atingir as expectativas do professor, o qual, por fim, fez uma avaliação da resposta dada pelo aluno. A organização desse padrão conversacional é percebida pelos participantes, de acordo com Garcez (2006, p. 69, grifos do autor):

\footnotetext{
[...] os participantes concordam que o que estão fazendo juntos se faz mediante uma organização interacional tal que se outorga a um certo participante, tipicamente aquele identificável como "professor", o direito de fazer perguntas insinceras, mais propriamente chamadas de perguntas de informação conhecida, perguntas-teste, perguntas para demonstração, ou outros termos que apontam para o caráter institucional do que se está fazendo naquilo que reconhecemos como sendo fala-em-interação de sala de aula.
}

As perguntas realizadas pelo professor servem, por exemplo, como forma de verificar se os alunos têm domínio ou não de um determinado conteúdo escolar, o que restringe as interações professor-alunos em sequências pouco produtivas para a participação efetiva dos discentes durante as aulas. Contudo, assim como Garcez (2006), 
acreditamos que a eliminação da sequência IRA da sala de aula também não é o caminho mais adequado, pois, em determinados contextos escolares, ela é necessária. Para ilustrarmos, como, às vezes, tal sequência é relevante, recorremos à interação ${ }^{5}$ ocorrida na segunda aula, quando a professora quer retomar os estudos da última oficina, a Oficina 1 , e se vale dessas sequências.

\section{S1_Aula 1_03_07_14}

\begin{tabular}{|c|c|}
\hline ANA & $\begin{array}{l}\text { A gente (.) se dividiu pra fazer um trabalho né? Cada } \uparrow u m \text { ia } \uparrow \text { lá na biblioteca e ia dizendo pra } \\
\text { profe o que queria escrever é ou não é? }\end{array}$ \\
\hline ALUNOS & É ((os alunos respondem juntos $))$ \\
\hline ANA & †É né? E o que que é que a gente foi escrever lá? \\
\hline ALUNO1 & As coisas $=(($ um aluno no fundo da sala responde $))$ \\
\hline ALUNA2 & $=$ As coisas que queria $=(($ uma aluna próxima à professora responde $))$ \\
\hline ALUNA3 & $=$ As coisas que gostava $=(($ uma aluna responde $))$ \\
\hline ALUNA4 & $=$ As coisas que gosta $=(($ uma aluna responde $))$ \\
\hline ANA & A:::h como é que era o nome desse texto que a gente foi fazer? Alguém lembra? \\
\hline ALUNA2 & O ÁLBUM \\
\hline ALUNOS & O álbum ((outros alunos falam)) \\
\hline ANA & Não não é álbum \\
\hline ALUNA5 & É tipo uma história \\
\hline ALUNA6 & ${ }^{\circ} \mathrm{O}$ autorretrato ${ }^{\circ}(($ uma menina no fundo da sala responde $))$ \\
\hline ANA & A:::h alguém lembrou deixa eu ver \\
\hline ALUNOS & Autorretrato ((grande parte dos alunos falam juntos)) \\
\hline ANA & Autorretrato \\
\hline
\end{tabular}

No caso da professora, as informações que ela gostaria de verificar junto aos alunos seriam se todos lembravam que, na última aula, eles haviam iniciado uma atividade diferente e se todos se lembravam do gênero autorretrato. Destacamos ainda que Ana já conhecia todas as respostas, apenas questionava os alunos como forma de conferir se eles dispunham ou não daquelas informações. Nota-se, inclusive, que inúmeras respostas ocorrem até os alunos chegarem à informação que a professora quer obter. Assim, Ana não se preocupa em questionar a resposta dada por grande parte dos alunos "um álbum", dela fazendo simplesmente uma avaliação negativa "não, não é um álbum", pois o que realmente importava à professora era que os alunos chegassem ao nome do gênero que estava sendo estudado.

Avançando nas discussões sobre os padrões interacionais presentes em sala de aula, destaca-se o revozeamento (O'CONNOR; MICHAELS, 1996; GARCEZ, 2005). Essa prática pode ser vista como uma forma que propicia maior tempo de interação e construção de sentidos entre professor-alunos. Escolhemos para ilustrá-la eventos da sala de aula no momento em que a professora está no processo de coconstrução do conceito do gênero autorretrato. É interessante observar que, em vários momentos de sua pilotagem do projeto didático, Ana inicia verificando informações e, para isso, se vale de sequências IRA, mas, a partir das interações com os alunos, passa à prática do revozeamento.

\footnotetext{
${ }^{5}$ Para fins de transcrição de dados aqui apresentados, fizemos adaptações a partir das convenções de transcrições propostas por Schnack, Pisoni e Ostermann (2005, p. 104), ver Anexo A. 


\section{S2 - Aula 1_30_06_14}

$\begin{array}{ll}\text { ANA } & \text { Alguém já ouviu falar no autorretrato? } \\ \text { ALUNO 1 } & \text { Eu não= ((somente um aluno responde, a gravação não mostra o rosto)) } \\ \text { ALUNOS } & \text { =Nã:::o ((todos falam juntos)) } \\ \text { ANA } & \text { O que que é o autorretrato então? } \\ \text { ALUNO-DUDA } & \text { É uma coisa assim ((o aluno forma um quadrado com as mãos)) } \\ \text { ANA } & \text { É uma folha assim? } \\ \text { ALUNO-DUDA } & \text { É uma foto } \\ \text { ANA } & \text { A:::h é uma foto m::: o que mais pode ser um autorretrato? ((silêncio)) Será que só a foto } \\ & \text { é um autorretrato? }\end{array}$

Com o intuito de iniciar o trabalho, a professora faz a seguinte pergunta: "Alguém já ouvir falar do autorretrato?" Trata-se de uma questão fechada, que poderia levar à sequência IRA, tomando $o$ não como resposta definitiva dos alunos e passando o professor a explicar o conceito do gênero. Ana, entretanto, muda o curso de seu agir. A partir do questionamento "O que que é o autorretrato então?", inicia uma série de interações nas quais a professora faz uso da prática do revozeamento (O'CONNOR; MICHAELS, 1996; CONCEIÇÃO; GARCEZ, 2005). Essa estrutura interacional caracteriza-se por ser iniciada com uma pergunta feita pelo professor - normalmente uma pergunta aberta que o professor pode saber ou não a resposta - a qual é respondida pelo aluno e, em seguida, ao tomar o turno novamente, o professor reproduz o enunciado do aluno, como formar de verificar se entendeu a resposta dada, sendo que a mesma pode ser retificada ou ratificada pelo aluno ou outro colega.

Por dar autonomia a ambos os participantes da interação, o revozeamento apresenta uma perspectiva mais democrática, pois dá voz aos alunos, oportunizando coprodução do conhecimento em sala de aula e a formação de um sujeito mais crítico. Tal posicionamento é percebido na sala de aula do $1^{\circ}$ ano, pois Ana não deixa de pilotar seu projeto de ensino (delineado em planejamento), mas tenta coconstruir os conceitos a serem trabalhados em conjunto com seus alunos. Assim, na prática de sala de aula de Ana, há um misto de sequências IRA com prática de revozeamento, como aponta a sequência a seguir:

\section{S4_Aula_03_07_14}

\begin{tabular}{|c|c|}
\hline ANA & $\begin{array}{l}\text { Mas eu quero saber o seguinte vamos olhar para este autorretrato do Van Gogh (.) dá pra gente } \\
\text { olhando pra ele falar como ele é? ((enquanto a professora fala, ela segura o autorretrato de Van } \\
\text { Gogh em suas mãos)) }\end{array}$ \\
\hline ALUNO1 & Legal \\
\hline ALUNO2 & Legal \\
\hline ANA & $\begin{array}{l}\text { Tá só um pouquinho (.) não vamos chegar nessa parte assim vamos pensar na parte } \uparrow \text { física dele } \\
\text { como é que ele é ele é bonito?= }\end{array}$ \\
\hline ALUNO2 & $=$ Bonito $=$ \\
\hline ALUNO3 & $=$ Bonito $=$ \\
\hline ANA & $=$ Ou é feio? \\
\hline ALUNO4 & $=$ Feio $=$ \\
\hline ANA & $\begin{array}{l}\text { Vocês acharam ele bonito (.) o::::h temos já uma coisa aí ele é bonito o que que mais a gente pode } \\
\text { dizer dele? }\end{array}$ \\
\hline ALUNOS & XXXX ((muitos alunos falam ao mesmo tempo)) \\
\hline ALUNA5 & $=$ ELE É ESPERTO= \\
\hline
\end{tabular}




\begin{tabular}{|c|c|}
\hline ALUNA6 & =ELE É ESPERTO \\
\hline ANA & $\begin{array}{l}\text { Só um pouquinho olhando assim na foto no autorretrato dele na imagem a gente consegue dizer } \\
\text { que ele é esperto? }\end{array}$ \\
\hline ALUNOS & N:::ão ((os alunos falam juntos)) \\
\hline ANA & Dá pra saber se ele é esperto ou não? \\
\hline ALUNOS & N:::ão ((os alunos falam juntos)) \\
\hline ANA & $\begin{array}{l}\text { Não né? Pra isso a gente teria que estudar outras coisas fazer uma pesquisa vamos pensar assim } \\
\text { olhando pro autorretrato vamos pensar na parte mais física dele= }\end{array}$ \\
\hline ALUNO7 & $=$ Ele tem barba \\
\hline ANA & Ele tem barba \\
\hline ALUNA8 & Ele tem cabelo \\
\hline ANA & Como é que é o cabelo dele? \\
\hline ALUNOS & [Laranja] \\
\hline ANA & $\begin{array}{l}\text { Só um pouquinho (.) o::h lembra como é que que é quando eu faço assim com a mão? Então tá } \\
\text { gente (.) o cabelo dele alguém sabe porquê assim teve gente que disse ali ai ele é } \uparrow \text { era laranja mais } \\
\text { quando a gente fala do cabelo existe um jeito assim mais específico que a gente pode dizer dessa } \\
\text { cor do cabelo dele que tá meio avermelhado não tá meio avermelhado mesmo esse cabelo dele? }\end{array}$ \\
\hline ALUNOS & S::im ((os alunos respondem juntos)) \\
\hline ANA & $\begin{array}{l}\text { Tá meio avermelhado até a gente podia dizer que ele é ruivo porque quem tem o cabelo meio } \\
\text { avermelhado é ruivo sabiam? }\end{array}$ \\
\hline
\end{tabular}

Durante as interações que compõem o excerto S4, percebemos que Ana explora o conteúdo temático do gênero autorretrato, propondo uma leitura desse gênero na modalidade visual. A pergunta inicial levaria a uma resposta que descrevesse verbalmente a pintura. Entretanto, alguns alunos, ao realizarem a leitura do não verbal, apontam que Van Gogh é legal, adjetivo que caracterizaria um plano psicológico, afastando-se do plano físico pretendido pela professora, muito possivelmente porque usam esse adjetivo para várias coisas. Ao receber tal resposta, provavelmente inesperada para ela, a professora reorienta seu agir, voltando ao seu planejamento inicial, dizendo que "Tá só um pouquinho (.) não vamos chegar nessa parte assim vamos pensar na parte física dele como é que ele é ele é bonito?”. Como mais alunos respondem que é bonito, incorpora esse adjetivo à descrição, ou seja, revozeia seus alunos, e faz uma pergunta aberta "Vocês acharam ele bonito (.) o:::h temos já uma coisa aí ele é bonito o que que mais a gente pode dizer dele?"

Ana nunca deixa de pilotar seu projeto de ensino, mas, ao mesmo tempo, demonstra coconstruir os conceitos com seus alunos, daí, inclusive, o uso variado de a gente. Ao se valer de uma pintura para levantar as principais características do gênero, a professora propõe a construção de sentido desse gênero a partir de um código já conhecido por seus alunos, o não verbal (não podemos esquecer que estamos diante de uma turma que começou recentemente seu processo de alfabetização). Com isso, evidencia respeitar as capacidades de linguagem demonstradas por seus aprendizes.

Ao ver que seus alunos insistem com adjetivos que vão além da descrição física proposta por ela, a professora faz uma readaptação do que havia prescrito em seu planejamento (nele, Ana tinha previsto falar das características físicas de Van Gogh). Em seu trabalho real/concretizado, no curso do agir, precisou retomar algumas coisas antes de dar continuidade ao estudo do gênero. O excerto S5 exemplifica como a professora explorou as características que vão além de bonito e feio, como algumas psicológicas, acessíveis por meio da fisionomia de Van Gogh. 


\section{S5_Aula_03_07_14}

$\begin{array}{ll}\text { ANA } & \text { A gente olhando pra ele a gente consegue dizer se ele está feliz se ele está triste? } \\ \text { ALUNO1 } & \text { SIM } \\ \text { ALUNO2 } & \text { Tá brabo } \\ \text { ALUNO3 } & { }^{\circ} \text { Triste }^{\circ} \\ \text { ANA } & \begin{array}{l}\text { Muito bem podemos dizer até que talvez ele esteja brabo a cara dele realmente está parecendo um } \\ \text { pouco braba né? É né? Mas feliz ele não tá né? Olhando assim né? }\end{array}\end{array}$

Ainda que Ana tenha feito uma pergunta fechada "feliz ou triste?", ao obter uma resposta diferente da esperada "tá brabo", não hesita em revozeá-la e retomar sua pergunta inicial de forma diferente "Mas feliz ele não tá né?".

A escolha do autorretrato de Van Gogh como forma inicial de delimitar o conteúdo temático do gênero, de acordo com as interações apresentadas, corroborou para que os alunos conseguissem compreender o que pode ser dito nesse gênero ${ }^{6}$. O uso desse material pela professora vai ao encontro do que Machado (2007, p. 94) descreve como uma das atribuições do professor: "[...] d) selecionar instrumentos adequados a cada situação [...]" Refletir sobre essa questão é de suma importância nesse trabalho em específico, pois o público-alvo do PDG sobre o autorretrato eram alunos do $1^{\circ}$ ano do Ensino Fundamental, o que delegou à professora o papel de averiguar quais eram as dimensões ensináveis do gênero que poderiam ficar ao alcance desses alunos.

Além do trabalho com o autorretrato de Van Gogh, outros exemplares do gênero, como o autorretrato da Palhacinha Marronzinha (imagético, assim como o de Van Gogh), um autorretrato produzido em formato digital (escrito) e outros dois produzidos por alunos do Ensino Médio (material escrito cedido por uma professora que também trabalhou com o mesmo gênero, mas em um nível de escolaridade diferente), serviram para delimitar tanto o conteúdo temático quanto as demais dimensões constitutivas do gênero. Para ilustrar a articulação entre as aprendizagens em sala de aula e escrita do autorretrato, tendo a professora como escriba, apresentamos a Produção Final de um dos alunos na figura 1 a seguir.

O autorretrato sintetiza o que vínhamos discutindo e apontando neste artigo: estamos diante de uma classe de $1^{\circ}$ ano, com alunos não alfabetizados, o que os levou a ditar à professora o que desejariam ver escrito em seu texto final, o qual será apresentado ao Conselho de Classe. As marcas do texto oral são evidentes, há menos planejamento, com as características sendo apresentadas à medida que vêm à memória do aluno. Assim, o texto começa com "Eu gosto de brincar". Na próxima frase, o foco está em uma característica positiva, "Eu sou legal", sem argumentos anteriores que permitam apoiá-la. As características psicológicas, agora, dão lugar às físicas: "Meu olho é um pouco verde, eu sou alto, sou um pouco magro". Após, o texto do aluno volta-se às coisas de que gosta, faz uma avaliação: "Minha vida é boa", e continua, sem concluir, com outro gosto. A professora comporta-se como escriba, sem interferir na produção dos alunos.

\footnotetext{
${ }^{6}$ Embora a análise proposta pela professora estivesse pautada no autorretrato "imagético" e os alunos, ao final do PDG, produzissem um autorretrato escrito, o que poderia levar à conclusão de que o conteúdo temático dos dois não fosse equiparável, compreendemos a posição adotada por Ana. Dentro do contexto de uma sala de aula de $1^{\circ}$ ano do Ensino Fundamental, certamente faz muito mais sentido partir de uma concepção mais concreta de autorretrato, o imagético, do que já introduzir o gênero em sua forma escrita, uma vez que, nesse caso, como os alunos ainda estavam em processo de alfabetização, seria partir de algo muito abstrato para aquele momento.
} 


\section{Figura 1 - Produção Final do aluno $\mathrm{E}$}

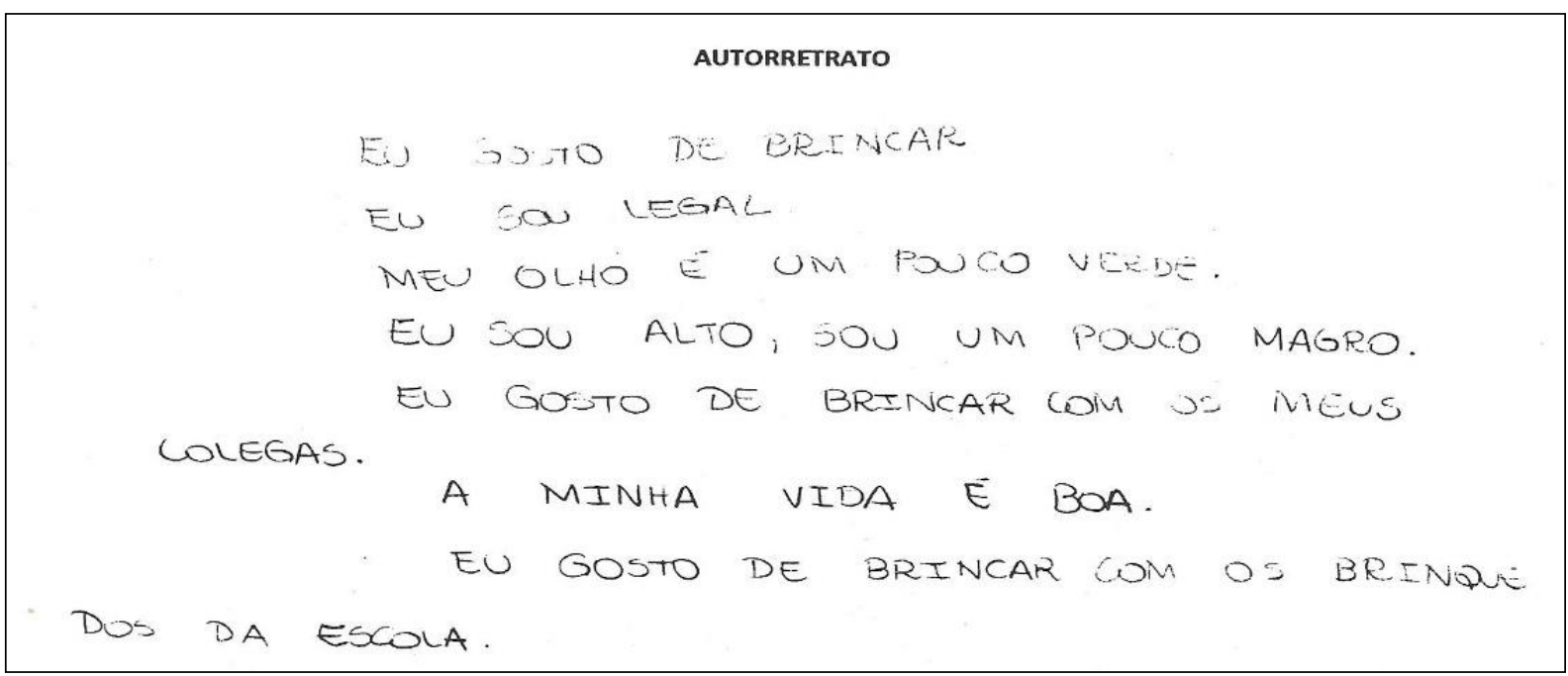

Ana respeita os limites de seus alunos, as capacidades linguístico-discursivas por eles apresentadas, considerando fortemente o contexto de sua sala de aula. Ou seja, o exemplo que acabamos de trazer mostra a compreensão do gênero por um aluno de $1^{\circ}$ ano, uma vez que é possível perceber que houve o entendimento de que, no autorretrato, é utilizada a primeira pessoa do singular (eu), é necessária a enumeração de características físicas "Meu olho é um pouco verde", por exemplo, e características psicológicas, como "legal", além da descrição de atividade de que o aluno gosta "Eu gosto de brincar com os meus colegas".

Pensando nisso, chegamos ao que Guimarães (2016) chamou de gênero praticado, entendendo que a prática social do gênero é intrínseca ao seu ensino, quando se trata da opção metodológica de PDG. No caso, estamos diante de uma prática de letramento dirigida a um contexto sociocultural da esfera da escola (a reunião do Conselho de Classe), lugar de negociação/transformação das posições assumidas pelos alunos ao escreverem seus autorretratos ${ }^{7}$. Dessa forma, estamos entendendo práticas de letramento (STREET, 2006) como constitutivas de uma identidade escolar, tanto do aluno quanto do professor. A partir da perspectiva do gênero praticado (GUIMARÃES, 2016), é possível verificar que Ana faz adaptações necessárias para que o autorretrato seja um objeto de ensino no $1^{\circ}$ ano do Ensino Fundamental. Para isso, são enfocadas as características mais superficiais do gênero autorretrato (o contexto de produção do gênero, a necessidade de ser escrito em $1^{\circ}$ e os assuntos pertinentes ao gênero: nome, idade, coisas de que gostam ou não gostam), as quais Ana avalia como sendo pertinentes ao seu projeto de ensino e ao momento sócio-histórico de seus alunos, e que também são adequadas à prática social que ela almeja inserir seus alunos a partir da produção do gênero.

\footnotetext{
7 Sabemos que a produção final do aluno $\mathrm{E}$ atende parcialmente às características do autorretrato, distanciando-se de seu gênero de referência. Contudo, ressalta-se que a produção inicial dos alunos era composta, na maior parte das vezes, por apenas uma frase, e que é possível notar uma evolução na direção do gênero proposta, quando comparadas as duas produções. É importante ainda enfatizar que Ana, após a etapa das produções finais, fez em conjunto com os alunos uma produção coletiva em que organizou o texto de forma, por exemplo, que as características físicas fossem apresentadas de modo a permitir o reconhecimento, seguidas de características psicológicas. Ela retomou as características composicionais mais marcantes do gênero, com a finalidade de auxiliar a reescrita das produções, última etapa do PDG.
} 
O que se torna relevante neste estudo é que o curso do agir da professora é modificado em alguns momentos no trabalho real/concretizado pelas participações dos alunos, o que corrobora para a constatação de que a professora entende a sala de aula como um locus de interação, o que procuramos mostrar através da análise de sequências interativas que comprovam que Ana não ignora as participações de seus alunos, ao contrário, as incorpora ao seu fazer didático.

\section{CONSIDERAÇÕES FINAIS}

Para finalizar, retomamos a definição da profissionalidade do professor que se faz, principalmente, a partir de sua capacidade de pilotar um projeto de ensino predeterminado, que não está acabado, e que pode, por isso, ser modificado durante o curso do agir do professor (BRONCKART, 2006). Dessa forma, seguimos Malabarba (2015) para afirmar que se pode modificar a proposta de Bronckart (2006), para incluir mais nitidamente a coconstrução do conhecimento em sala de aula (o que mostramos através das práticas de revozeamento).

Ao ressignificar o conceito de linguagem como interação nas suas práticas de interação com os alunos, enfim, em seu trabalho, Ana revela uma articulação entre o que aprendeu no decorrer da formação continuada cooperativa e da sua prática profissional. Isso nos leva a perceber um avanço em direção à mudança de paradigma, à medida que a interação em sala de aula passa a ser vista como algo profícuo para a aprendizagem, mesmo que o professor tenha que reorientar o seu agir, sempre que necessário. Ana não está preocupada com que seus alunos produzam um texto descontextualizado, a partir de um modelo dado. Ela poderia ter fornecido uma espécie de autorretrato com lacunas para os alunos completarem de acordo com suas próprias características. Como ela realmente quer ouvi-los e quer que sejam ouvidos, deixa-os expressarem-se livremente, procurando fazer com que os alunos pratiquem a produção do gênero e discutam sua produção na interação em sala de aula. Mesmo que o texto produzido guarde apenas algumas das características do gênero focado, apresente-se como uma silhueta do que seria idealmente preconizado, é possível nele reconhecer a preocupação do aluno em se apresentar para os professores que compõem o Conselho de Classe ${ }^{8}$.

Ao internalizar o conceito de linguagem como interação, ao atualizá-lo concretamente na sua relação com os alunos em sala de aula via interações eivadas de revozeamento, ao quebrar o paradigma de que o $1^{\circ}$ ano é sinônimo apenas de alfabetização, a professora Ana mostra que conceitos epistemológicos trabalhados numa formação são significativos para o seu desenvolvimento profissional.

\footnotetext{
${ }^{8} \mathrm{O}$ emprego de uma opção metodológica como o PDG sobre o autorretrato numa série composta por alunos não-alfabetizados aponta para o quanto a professora Ana afastou-se do paradigma tradicional do ensino da alfabetização. Por outro lado, é possível perceber que os alunos também progrediram especialmente em dois aspectos: o domínio de características mais superficiais do gênero, fazendo com que a produção final tomasse os contornos característicos de um autorretrato; mas, sobretudo, a oportunidade de inserção em práticas de letramento, de forma simultânea à própria alfabetização. Os alunos se inseriram em diversos eventos de letramento (STREET, 2012) durante as aulas. Tais conhecimentos, então, não ficaram restritos à produção do autorretrato, mas, sim, oportunizaram o aperfeiçoamento da leitura e da escrita como práticas sociais.
} 
Dessa forma, refletir sobre as práticas interacionais em sala de aula reforçou a premissa de que a proposição de novas formações continuadas de professores, feitas à semelhança da que acompanhamos, é a chave para o aperfeiçoamento docente. Em suma, é caminho mais eficaz para instrumentalizá-los, no sentido vygostkiano do termo, fazendo com que consigam conduzir seus projetos de ensino dentro de propostas renovadoras.

\section{REFERÊNCIAS}

ALMEIDA, A. P. Docência de língua materna: o professor como ator do seu próprio agir. 2015. $174 \mathrm{f}$. Tese (Doutorado em Linguística Aplicada) - Programa de Pós-Graduação em Linguística Aplicada, Universidade do Vale do Rio dos Sinos (UNISINOS), São Leopoldo, 2015. Documento em PDF.

BAKHTIN, M. Estética da criação verbal. Tradução do russo por Paulo Bezerra. 6. ed. São Paulo: Martins Fontes, 2011.

BARTIKOSKI, F. V. M. Projeto didático de gênero em sala de aula de progressão continuada: um estudo de caso. 2013. 83 f. Trabalho de Conclusão de Curso (Licenciatura em Letras) - Curso de Letras: Habilitação: Português, Universidade do Vale do Rio dos Sinos (UNISINOS), São Leopoldo, 2013.

Projeto didático de gênero: retomando práticas e avaliando. 2017. 121 f. Dissertação (Mestrado em Linguística Aplicada) -- Programa de Pós-Graduação em Linguística Aplicada, Universidade do Vale do Rio dos Sinos (UNISINOS), São Leopoldo, 2017.

BARTHOLOMEU, I. C. S. Projeto didático de gênero: um estudo a partir do modelo didático de gênero e das capacidades de linguagem mobilizadas em trabalho com cartas de reclamação. 2016. 222 f.

Dissertação (Mestrado em Letras) - Programa de Pós-Graduação em Estudos Linguísticos, Universidade Federal de Minas Gerais (UFMG), Belo Horizonte, 2016.

BRAGA, N. F. F. Gêneros e projetos: uma análise dos conceitos de Projeto de Letramento, Projeto Didático de Gênero e Sequência Didática. 2017. 132 f. Dissertação (Mestrado em Educação) - Programa de Pós-Graduação em Educação, Universidade Federal de Juiz de Fora (UFJF), Juiz de Fora, 2017.

BRONCKART, J. P. Atividade de linguagem, texto e discurso: por um interacionismo sociodiscursivo. São Paulo: EDUC, 1999.

Commentaires conclusifs: pour um développement collectif de l'interactionnisme socio-discursif. Calidoscópio, São Leopoldo, v. 2, n. 2, p. 113-23, jul./dez. 2004. 2006. Atividade de linguagem, discurso e desenvolvimento humano. Campinas, SP: Mercado de Letras,

O agir nos discursos: das concepções teóricas às concepções dos trabalhadores. Campinas: Mercado de Letras, 2008.

CARNIN, A. Na escrita do professor, um percurso possível para a análise do (seu) desenvolvimento profissional. 2015. 139 f. Tese (Doutorado em Linguística Aplicada) - Programa de Pós-Graduação em Linguística Aplicada, Universidade do Vale do Rio dos Sinos (UNISINOS), São Leopoldo, 2015. Documento em PDF.

CONCEIÇÃO, L. E.; GARCEZ, P. M. O revozeamento no discurso da escola pública cidadã. Intercâmbio, São Paulo, v. 12, p. 1-10, 2005. Disponível em: <http://revistas. pucsp.br/index.php/intercambio/article/view/3941>. Acesso em: 05 jun. 2017.

DOLZ, J.; SCHNEUWLY, B. Gêneros orais e escritos na escola. Tradução e Organização de Roxane Rojo e Glaís Sales Cordeiro. Campinas: Mercado de Letras, 2004.

FRANCHI, C. Linguagem: atividade constitutiva. Cadernos de Estudos Linguísticos, Campinas, v. 22, p. 9-39, jan./jun. 1992.

GARCEZ, P. M. A organização da fala-em-interação na sala de aula: controle social, reprodução do conhecimento, construção conjunta do conhecimento. Calidoscópio, São Leopoldo, v. 4, n. 1, p. 60-65, jan./abr. 2006.

GERALDI, J. W. (Org.) O texto na sala de aula: leitura e produção. 7. ed. Cascavel: ASSOESTE, 1991. Originalmente publicado em 1984. 
GUIMARÃES, A. M. M.; DREY, R. F.; CARNIN, A. Parece difícil e é mesmo: sobre a dificuldade de falar sobre o trabalho docente na sala de aula. In: CORREA, M. C.; GUIMARÃES, A. M. M. (Org.). Formação continuada de professores de língua portuguesa: desafios e possibilidades. Santa Maria: PPGL Editores/UFSM, 2012. p. 155-186.

GUIMARÃES, A. M. M.; KERSCH, D. F. (Org.). Caminhos da construção: Projetos Didáticos de Gênero na sala de aula de língua portuguesa. Campinas, SP: Mercado de Letras, 2012.

(Org.). Caminhos da construção: Projetos Didáticos de Gênero na sala no domínio do argumentar. Campinas, SP: Mercado das Letras, 2014.

GUIMARÃES, A. M. M.; CARNIN, A.; KERSCH, D. F. (Org.). Caminhos da construção: reflexões sobre projetos didáticos de gênero. Campinas, SP: Mercado de Letras, 2015.

GUIMARÃES, A. M. M. Do saber fazer ao poder fazer: a importância de uma formação continuada que dê voz ao professor. In: FLAEL: FÓRUM DE LINGUÍSTICA APLICADA E ENSINO-

APRENDIZAGEM DE LÍNGUAS, 5., 2016. Universidade Federal do Ceará, Fortaleza, 2016.

LISBOA, I. V. P. A análise linguística como uma dimensão do estudo do gênero textual através de projetos didáticos de gênero. 2014. 139 f. Dissertação (Mestrado em Linguística Aplicada) - Programa de Pós-Graduação em Linguística Aplicada, Universidade do Vale do Rio dos Sinos, São Leopoldo, 2014.

MACHADO, A. R. Por uma concepção ampliada do trabalho do professor. In: GUIMARÃES, A. M. M.; MACHADO, A. R.; COUTINHO, A. (Org.) O interacionismo sociodiscursivo: questões teóricas e metodológicas. Campinas: Mercado de Letras, 2007. p. 77-97.

MALABARBA, T. O percurso do agir interacional no trabalho docente: do projeto de ensino às participações contingentes em sala de aula de língua inglesa. 2015. $198 \mathrm{f}$. Tese (Doutorado em Linguística Aplicada) - Programa de Pós-Graduação em Linguística Aplicada, Universidade do Vale do Rio dos Sinos, São Leopoldo, 2015.

MARQUES, R. G. Projeto didático de gênero como possibilidade para o ensino da língua materna e o desenvolvimento das capacidades de linguagem de alunos multirrepetentes. 2014. $161 \mathrm{f}$. Dissertação (Mestrado em Linguística Aplicada) - Programa de Pós-Graduação em Linguística Aplicada, Universidade do Vale do Rio dos Sinos, São Leopoldo, 2014.

O'CONNOR, M.; MICHAELS, S. Shifting participant frameworks: Orchestrating thinking practices ingroup discussion. HICKS, D. (Org.). Discourse, learning and schooling. Cambridge: Cambridge University Press, 1996. p. 63-103.

SCHNACK, C. M.; PISONI, T. D.; OSTERMANN, A. C. Transcrição de fala: do evento real à representação escrita. Entrelinhas, São Leopoldo, v. 2, n. 2, maio/ago. 2005.

SINCLAIR, J.M.; COULTHARD, M. Toward an Analysis of Discourse. London: Oxford University Press, 1975.

STREET, B. Perspectivas interculturais sobre o letramento. Filologia e Linguística Portuguesa, São Paulo, n. 8, p. 465-488, jul. 2006.

Eventos de letramento e práticas de letramento: teoria e prática nos novos estudos de letramento. MAGALHÃES, I. (Org.). Discursos e práticas de letramento. Campinas, Mercado de Letras, 2012. p. 69. 92.

VOLOCHÍNOV, V. N. Marxismo e filosofia da linguagem. Tradução do francês de Michel Lahud e outros. 12. ed. São Paulo: Hucitec, 2006.

\section{ANEXO - CONVENÇÕES DE TRANSCRIÇÃO ADAPTADAS}

$\begin{array}{ll}\text { Convenções de transcrição } & \\ - & \text { Interrupção abrupta da fala } \\ = & \text { Fala colada à elocução anterior } \\ (.) & \text { Micropausa } \\ (0,4) ;(0,5) ;(1,8) ; \text { etc. } & \text { Intervalo da pausa } \\ \text { Sublinhado } & \text { Sílaba, palavra ou som acentuado } \\ {[\quad]} & \text { Falas sobrepostas } \\ : & \text { Alongamento de som } \\ >< & \text { Fala mais rápida }\end{array}$

GUIMARÃES, Ana Maria de Mattos; BARTIKOSKI, Fernanda Vanessa Machado. Práticas de linguagem em sala de aula como reveladoras de mudanças na profissionalidade docente. Linguagem em (Dis)curso - LemD, Tubarão, SC, v. 18, n. 2, p. 359-373, maio/ago. 2018. 


$\begin{array}{ll}<> & \text { Fala mais lenta } \\ \circ \circ & \text { Fala com volume mais baixo } \\ \text { LETRAS MAIÚSCULAS } & \text { Fala com volume mais alto } \\ (\quad) & \text { Dúvida na transcrição } \\ \text { XXXX } & \text { Texto inaudível } \\ (()) & \text { Comentários do transcritor } \\ \downarrow & \text { Entonação descendente } \\ \uparrow & \text { Entonação ascendente }\end{array}$

Recebido em: 10/08/17. Aprovado em: 12/04/18.

Title: Language practices in the classroom as revealing changes in teacher's professionalism Authors: Ana Maria de Mattos Guimarães; Fernanda Vanessa Machado Bartikoski

Abstract: This article reflects upon the importance of analyzing teacher-student interactions as part of the teacher's professionalism, projecting their ability to guide a predetermined teaching project (BRONCKART, 2006). In other words, it can be modified by the possibilities of co-constructing knowledge in the classroom during the course of his/her action. In order to show this movement, it presents extracts of interactions with one of the teachers who participate in a cooperative service education project. By re-signifying the concept of language in their practices of interaction with students, that means, in their real/accomplished work (GUIMARÃES et al., 2012), she reveals an articulation between what she has learnt during the project and her professional practice, which is specially noticed in the constant practice of revoicing (O'CONNOR; MICHAELS, 1996). As a result, the necessity of projects that rethink Portuguese Language teaching in a process that emphasizes the importance of teacher-student interactions is highlighted.

Keywords: Mother tongue. Teaching. Interaction. Teacher action.

Título: Prácticas de lenguaje en clase como reveladoras de cambios en la profesionalidad docente

Autores: Ana Maria de Mattos Guimarães; Fernanda Vanessa Machado Bartikoski

Resumen: Este artículo reflexiona sobre la importancia de analizarse las interacciones professor-alumno como parte de la profesionalidad del profesor, proyectando su capacidad de pilotar un proyecto de enseñanza predeterminado (BRONCKART, 2006). Es decir, que puede, durante el curso de su acción, ser modificado por las posibilidades de coconstrucción del conocimiento en clase. Para mostrar ese movimiento, trae ejemplos de interacciones de una de las profesoras participantes del proyecto de formación continua cooperativa. Al resignificar el concepto de lenguaje en sus prácticas de interacción con los alumnos, en fin, en su trabajo real/concretizado (GUIMARÃES et al., 2012), revela una articulación entre lo que ha aprendido a lo largo de su formación y su práctica profesional, observada, especialmente, en la constante práctica del re-expresar (O'CONNOR; MICHAELS, 1996). Se resalta, entonces, la necesidad de formaciones que repiensen la enseñanza de Lengua Portuguesa en un proceso que enfatiza la importancia de las interacciones professor-alumnos.

Palabras-clave: Lengua materna. Enseñanza. Interacción. Acción docente. 